\title{
Antegrade thoracic stent grafting during repair of acute Debakey type I dissection promotes distal aortic remodeling and reduces late open distal reoperation rate
}

\author{
Prashanth Vallabhajosyula, MD, MS, ${ }^{a}$ Wilson Y. Szeto, MD, ${ }^{a}$ Aaron Pulsipher, BS, ${ }^{a}$ \\ Nimesh Desai, MD, PhD, ${ }^{\text {a }}$ Rohan Menon, BS, ${ }^{\text {a }}$ Patrick Moeller, BS, ${ }^{a}$ Shenara Musthaq, \\ Alberto Pochettino, MD, ${ }^{b}$ and Joseph E. Bavaria, MD $^{\mathrm{a}}$
}

\begin{abstract}
Objective: Previously, we showed that antegrade stent grafting of the descending thoracic aorta during DeBakey type I dissection repair improves distal aortic remodeling. We assessed midterm outcomes of this reconstructive strategy compared with standard open repair.
\end{abstract}

\begin{abstract}
Methods: DeBakey type I dissections (non-Marfan, nontotal arch cases only) from 2005 to 2012 were retrospectively reviewed. One hundred eighty patients underwent standard open repair (standard group), and 62 patients underwent open repair plus stenting (stented group). Open repair entailed ascending aorta plus transverse hemiarch reconstruction under circulatory arrest, with variable aortic root work. Data was prospectively maintained.

Results: Preoperative parameters were similar. Patients in the stented group had longer circulatory arrest time and higher utility of antegrade cerebral perfusion $(P<.001)$. In-hospital/30-day mortality $(10 \%$ vs $14 \%$; $P=.51)$, stroke $(5 \%$ vs $8 \% ; P=.6)$, and paraplegia $(0 \%$ vs $1 \% ; P=1)$ were similar in the stented versus standard groups. Mean follow-up was $2.7 \pm 2.3$ and $2.2 \pm 2.1$ years. Actuarial survival in stented versus standard groups at 1 and 7 years was $86 \%$ versus $81 \%$ and $76 \%$ versus $60 \%(P=.5)$. Thoracic aorta false lumen obliteration was improved in the stented group $(82 \%$ vs $39 \% ; P<.001)$, along with improved freedom from open distal aortic reoperation rate ( $98 \%$ vs $90 \%$ at 6 years, $P=.1$ ). Endovascular distal aortic reintervention rate was higher in the stented group $(18 \%$ vs $3 \% ; P=.008)$, with zero mortality.
\end{abstract}

Conclusions: Antegrade stent graft deployment during acute DeBakey type I dissection repair is safe method to promote distal aortic remodeling without increasing postoperative or midterm mortality. This technique provides increased freedom from open distal aortic reoperations compared with standard open repair. (J Thorac Cardiovasc Surg 2014;147:942-50)

Even with current advances in surgical technique, circulatory management, and postoperative care, acute type A aortic dissection is associated with significant morbidity and mortality. ${ }^{1-10}$ Open surgical repair focuses on primarily on proximal aortic reconstruction with stabilization of the aortic arch. As an institutional practice, we perform ascending aorta replacement with transverse hemiarch reconstruction under circulatory arrest for type A aortic dissection, unless the tear site involves the aortic root or arch. The majority of patients present with DeBakey type I acute dissection, where the flap extends into the descending aorta ending at the aortic

From the Division of Cardiovascular Surgery, ${ }^{\text {a }}$ University of Pennsylvania, Philadelphia, Pa; and the Mayo Clinic, ${ }^{\mathrm{b}}$ Rochester, Minn.

Disclosures: Authors have nothing to disclose with regard to commercial support.

Read at the 93rd Annual Meeting of The American Association for Thoracic Surgery, Minneapolis, Minnesota, May 4-8, 2013.

Received for publication Sept 27, 2013; accepted for publication Oct 31, 2013; available ahead of print Dec 12, 2013.

Address for reprints: Prashanth Vallabhajosyula, MD, MS, Division of Cardiovascular Surgery, Silverstein 6, Hospital of the University of Pennsylvania, 3400 Spruce St, Philadelphia, PA 19104 (E-mail: prashanth.vallabhajosyula@uphs.upenn.edu). 0022-5223/\$36.00

Copyright (C) 2014 by The American Association for Thoracic Surgery

http://dx.doi.org/10.1016/j.jtcvs.2013.10.047 bifurcation. Standard current surgical practice does not address the dissection component involving the descending aorta. Several studies show that the remnant distal aortic pathology is associated with significant morbidity and mortality over long-term follow-up. In patients requiring open distal aortic reoperation, the mortality can be as high as $30 \% .{ }^{11-13}$

The advent of thoracic endovascular aneurysm repair (TEVAR) technology for proximal descending thoracic aorta (DTA) pathology opened the door for its potential utility in the repair of aortic dissection. ${ }^{14-19}$ In DeBakey type I dissection, patients presenting with malperfusion syndromes, where the associated mortality is significantly higher, we started performing concomitant TEVAR of the DTA to stabilize and improve true lumen flow in the remnant dissected aorta. We reported our initial experience and short-term outcomes of concomitant antegrade stent grafting of DTA during open dissection repair. ${ }^{7,20}$ It showed that this technology could be applied without increasing postoperative and short-term morbidity and mortality. In a concurrent series, we compared DeBakey type I acute aortic dissection patients who underwent standard open repair versus open repair plus antegrade 


\section{Abbreviations and Acronyms \\ $\mathrm{ACP}=$ antegrade cerebral perfusion \\ DTA $=$ Descending thoracic aorta \\ $\mathrm{CT}=$ computed tomography \\ $\mathrm{RCP}=$ retrograde cerebral perfusion \\ TAAA $=$ thoracoabdominal aortic aneurysm repair TEVAR $=$ thoracic endovascular aneurysm repair}

TEVAR of the DTA. Here we report our postoperative and midterm outcomes of this analysis.

\section{METHODS \\ Patients}

From June 2005 to June 2012, 398 patients (Marfan syndrome and total arch patients excluded) presented with ascending aortic dissection, of whom 242 presented with acute DeBakey type I aortic dissection. Diagnosis was confirmed by computed tomography (CT) scan and intraoperative transesophageal echocardiography before initiating surgery. The decision for standard open repair versus open repair plus antegrade stent grafting was surgeon preference. Stent grafting was adopted by 2 surgeons, whereas 3 others performed standard repair only. All patients were accrued in a contemporaneous fashion. Sixty-two patients underwent concomitant DTA stent grafting (stented group) and 180 had standard open repair (standard group). All patients had open distal transverse hemiarch anastomosis. All patients gave informed consent. Patients were followed prospectively. All patients received postoperative CT scan at discharge or at 1 month follow-up, and then every 6 months for the first 2 years, and then yearly thereafter. Institutional Review Board approval was obtained for this study.

Statistical analysis was performed using SPSS version 15.0 (IBM-SPSS Inc, Armonk, NY), and the Student $t$ test was used to assess differences between the groups for numerical parameters. The Fisher exact test was used for categorical parameters.

\section{Operative Technique}

All patients were emergently brought straight to the operating room, where the diagnosis was confirmed by CT imaging or echocardiography. Upon confirmation and obtaining informed consent, invasive monitoring was established using arterial line and pulmonary artery catheter. Upon induction, transesophageal echocardiography was performed to confirm the diagnosis and establish the operative strategy. When CT was not available to measure the proximal dissected DTA, echocardiography was used to obtain the diameter of the distal arch and the mid-DTA. Cardiopulmonary bypass constituted venous drainage via right atrial cannulation along with selective superior vena cava cannulation in patients elected for retrograde cerebral perfusion during circulatory arrest. Arterial cannulation for stented versus nonstented groups, respectively, was as follows: femoral artery $(\mathrm{n}=19, \mathrm{n}=26)$, axillary artery $(\mathrm{n}=16, \mathrm{n}=44)$, and direct true lumen cannulation of ascending aorta/arch $(n=27, n=110)$. In all cases, cerebral oximetry was used, and intraoperative carotid artery flow was confirmed by 2-dimensional Doppler. In addition, continuous electroencephalogram was used when available. Left ventricular vent was placed in all cases. During systemic cooling proximal aortic work was performed as previously described. The extent of aortic root work was determined by the proximal root and valve anatomy. Systemic cooling was performed to encephalogram flat line or for 50 minutes.

Circulatory arrest was initiated with either antegrade cerebral perfusion (ACP) or retrograde cerebral perfusion (RCP). ACP was established via axillary artery with proximal snare, or via direct ostial cannulation of the great vessels. For RCP, the superior vena cava was snared and cerebral flow was established at jugular venous pressure of 25 to $30 \mathrm{~mm} \mathrm{Hg}$. The remnant ascending aorta and majority of the lesser curve of the arch was resected. The dissection flap was then repaired with Teflon felt neomedia (DuPont, Wilmington, Del) to obliterate the false lumen in the proximal DTA and arch. In standard group patients, an appropriately sized Dacron graft (Vascutec Ltd, Renfrewshire, Scotland) was sewn to complete the transverse hemiarch reconstruction.

In the stented group, after creation of the Teflon felt neomedia, a 150mm length GoreTAG aortic stent graft (WL Gore \& Associates, Flagstaff, Ariz) was chosen at $15 \%$ larger than the measured proximal DTA diameter. The stent graft was deployed into the true lumen of the DTA under direct vision, with the proximal scallops of the GoreTAG abutting the origin of the left subclavian artery by the greater curve, and at the edge of repaired aorta along the lesser curve. The stent graft was then gently balloon dilated to attain proper apposition against the aortic wall. The stent graft was then secured proximally with 2 to 3 interrupted sutures, and then the Dacron graft transverse hemiarch anastomosis was performed in standard fashion. Along the lesser curve, whenever possible, the stent graft was incorporated into the Dacron graft suture line. The conduct of the rest of the operation was performed as previously described. ${ }^{20}$

\section{RESULTS}

\section{Preoperative Parameters and Operative Outcomes}

Preoperative risk factors were similar in the 2 groups, with $\sim 10 \%$ of patients requiring reoperative cardiac surgery at the time of presentation with DeBakey type I dissection (Table 1). Two out of 3 patients were men, and hypertension was the most common comorbidity in both groups. Stented group patients had higher rates of malperfusion syndrome at presentation ( $48 \%$ vs $39 \%)$, although this was not significant $(P=.23)$ (Table 2). Cardiopulmonary bypass ( $232 \pm 37$ vs $218 \pm 59$ minutes; $P=.07)$, aortic crossclamp $(171 \pm 40$ vs $143 \pm 50$ minutes; $P=.001)$, and total circulatory arrest ( $55 \pm 18$ vs $37 \pm 18$ minutes) times were longer in the stented group compared with the standard group. Aortic root replacement and aortic valve replacement rates were similar in both groups ( $P$ was nonsignificant). ACP strategy during circulatory arrest was employed more commonly in the stented group $(69 \%$ vs $24 \% ; P<.001)$, given the expected longer circulatory arrest time for antegrade stenting.

Overall, postoperative outcomes were similar (Table 2). Inhospital/30-day mortality was similar between the stented and standard groups $(10 \%$ vs $14 \% ; P=.51)$. The majority of this mortality in the stented group $(\mathrm{n}=5)$ occurred during the first 15 months of adopting the antegrade TEVAR technique as part of the DeBakey type I dissection repair. Since then there has been 1 death in the stented group, whereas mortality in the standard group has remained the same throughout follow-up. There were no differences in stroke ( $5 \%$ vs $8 \%$; $P=.57)$, renal failure $(21 \%$ vs $23 \% ; P=.45)$, or reoperation for bleeding $(11 \%$ vs $8 \% ; P=.45)$ rates. One patient experienced permanent paraplegia in the standard group (none in the stented group). Transient spinal cord ischemia rate was higher in the stented group ( $6 \%$ vs $2 \%$ ), although this was not significant $(P=.08)$. Hospital length of stay was similar $(16 \pm 12$ vs $14 \pm 12$ days; $P=.4)$. 
TABLE 1. Preoperative characteristics by patient group

\begin{tabular}{lccc}
\hline & Stented $(\mathbf{n}=\mathbf{6 2})$ & Standard $(\mathbf{n}=\mathbf{1 8 0})$ & $\boldsymbol{P}$ \\
\hline Age, y & $58.2 \pm 11.9$ & $59.4 \pm 13.9$ & .8 \\
Male, \% & $40(65)$ & $125(69)$ & .52 \\
Prior sternotomy & $6(10)$ & $19(11)$ & .8 \\
Prior AAA repair & $1(2)$ & $7(4)$ & .7 \\
$\quad$ (open or EVAR) & & & \\
Hypertension & $51(82)$ & $147(82)$ & 1 \\
Renal failure & $3(5)$ & $17(9)$ & .42 \\
Diabetes & $8(13)$ & $21(12)$ & .82 \\
Chronic lung disease & $6(10)$ & $18(10)$ & 1 \\
Malperfusion & $30(48)$ & $70(39)$ & .23 \\
\hline Dat
\end{tabular}

Data are presented as mean \pm standard deviation or $\mathrm{n}(\%)$. AAA, Abdominal aortic aneurysm; EVAR, endovascular aneurysm repair.

\section{Aortic Remodeling and Aortic Reinterventions}

Fifty-five patients $(98 \%)$ in the stented group had CT follow-up, compared with 120 patients $(77 \%)$ in the standard group. CT images were evaluated for complete or thoracic false lumen obliteration versus thoracic residual false lumen patency with or without abdominal segment. Antegrade DTA stenting promoted false lumen obliteration in the thoracic aorta compared with the standard group $(P<.001)$. Complete or thoracic false lumen obliteration rate was $82 \%$ $(n=45)$ in the stented group versus $39 \%(n=47)$ in the standard group (Table 3). Even though complete false lumen obliteration rates were similar ( $27 \%$ vs $23 \%$ ), thoracic false lumen obliteration rates were significantly improved in the stented group $(55 \%$ vs $16 \% ; P<.0001)$.

Distal aortic reintervention rates were evaluated in both groups with patients with any postoperative clinical follow-up (Figure 1). In the stented group, 11 patients underwent 11 single distal aortic reinterventions: 10 single TEVAR procedures, and 1 redo total arch procedure in a patient with type IA endoleak. This was during our early experience with the antegrade TEVAR technique (ie, within the first year). The overall open aortic distal reintervention rate was $1.8 \%(\mathrm{n}=1)$, and TEVAR-only reintervention rate was $18 \%(\mathrm{n}=10)$ in the stented group. There were zero multiple distal reinterventions in the stented group. In the standard group, 12 patients underwent 16 distal aortic reinterventions: 5 TEVAR procedures ( 2 patients with single TEVAR only), and 11 open distal aortic reinterventions (3 redo total arch procedures and 8 thoracoabdominal aortic aneurysm repair [TAAA] procedures). Three patients in the standard group had multiple distal aortic reinterventions, of which 1 patient had extent I TAAA repair, followed by extent III TAAA repair, followed by redo total arch repair (Figure 1).

The overall open distal reintervention rate was $9.2 \%$ $(\mathrm{n}=11)$ in the standard group, compared with $1.8 \%$ $(\mathrm{n}=1)$ in the stented group $(P=.1)$. The overall open thoracoabdominal aortic repair rate was $7 \%(\mathrm{n}=8)$ versus $0 \%$ in the standard versus stented groups $(P=.06)$. In contrast, TEVAR reintervention rates were significantly higher in the stented group ( $18 \%[\mathrm{n}=10]$ vs $4 \%[\mathrm{n}=5] ; P=.006)$. Perioperative mortality from all distal aortic reinterventions was $0 \%$ in the stented group, and $9 \%$ in the standard group $(P=1.0)$. Therefore, intraoperative antegrade TEVAR during acute DeBakey type I dissection repair improved thoracic false lumen obliteration rates on $\mathrm{CT}$ imaging

TABLE 2. Intraoperative and postoperative outcomes by patient group

\begin{tabular}{|c|c|c|c|}
\hline Outcome & Stented $(n=62)$ & Standard $(\mathbf{n}=180)$ & $\boldsymbol{P}$ \\
\hline \multicolumn{4}{|l|}{ Intraoperative } \\
\hline Root replacement & $10(16)$ & $36(20)$ & .57 \\
\hline Root reimplantation & $0(0)$ & $3(2)$ & .57 \\
\hline Aortic valve replacement & $8(13)$ & $37(21)$ & .22 \\
\hline Cardiopulmonary bypass time, min & $232 \pm 37$ & $218 \pm 59$ & .07 \\
\hline Aortic crossclamp time, min & $171 \pm 40$ & $143 \pm 50$ & .001 \\
\hline Retrograde plus antegrade cerebral perfusion & $8(13)$ & $19(11)$ & .64 \\
\hline Retrograde perfusion & $11(18)$ & $117(65)$ & $<.001$ \\
\hline Antegrade perfusion & $43(69)$ & $44(24)$ & $<.001$ \\
\hline Circulatory arrest time, min & $55 \pm 18$ & $37 \pm 18$ & .001 \\
\hline \multicolumn{4}{|l|}{ Postoperative } \\
\hline In-hospital/30-d mortality & $6(10)$ & $25(14)$ & .51 \\
\hline Stroke & $3(5)$ & $15(8)$ & .57 \\
\hline Permanent paraplegia & $0(0)$ & $1(1)$ & 1 \\
\hline Transient spinal cord ischemia & $4(6)$ & $3(2)$ & .08 \\
\hline Ischemic bowel & $3(5)$ & $7(4)$ & .71 \\
\hline Prolonged ventilation $(>24 \mathrm{~h})$ & $14(23)$ & $69(38)$ & .02 \\
\hline Renal insufficiency/failure & $13(21)$ & $42(23)$ & .86 \\
\hline With hemodialysis & $4(6)$ & $21(12)$ & .33 \\
\hline Reoperation for bleeding & $7(11)$ & $15(8)$ & .45 \\
\hline Length of Stay, d & $16 \pm 12$ & $14 \pm 12$ & .35 \\
\hline
\end{tabular}

Data are presented as mean \pm standard deviation or $\mathrm{n}(\%)$. 
TABLE 3. Status of the descending thoracic aorta false lumen status following DeBakey type I dissection repair

\begin{tabular}{lccc}
\hline Patient group & $\begin{array}{c}\text { Full } \\
\text { obliteration } \\
\text { of false lumen* }\end{array}$ & $\begin{array}{c}\text { Partial } \\
\text { obliteration } \\
\text { of false lumen* }\end{array}$ & $\begin{array}{c}\text { Fully patent } \\
\text { residual } \\
\text { false lumen }\end{array}$ \\
\hline Stented $(\mathrm{n}=55)$ & $15(27)$ & $30(55)$ & $10(18)$ \\
Standard $(\mathrm{n}=120)$ & $28(23)$ & $19(16)$ & $73(61)$
\end{tabular}

Data are presented as $\mathrm{n}(\%)$. *Full plus partial obliteration $=82 \%$ in the stented group, $39 \%$ in the standard group $(P<.001)$.

follow-up, and provided an endovascular platform in the thoracic aorta that promoted increased utility of TEVAR only as a distal aortic reintervention. Likely, the combination of improved thoracic false lumen obliteration, along with the increased utility of TEVAR for thoracic aortic reintervention in the stented group also led to a decreased requirement for open TAAA repair as a distal aortic reintervention in the stented group compared with the standard group $(0 \%$ vs $7 \% ; P=.06)$.

\section{Midterm Follow-up}

Mean follow-up was $2.7 \pm 2.3$ years and $2.2 \pm 2.1$ years in the stented and standard groups, respectively. Actuarial freedom from open distal aortic reintervention at 5 years was $98 \%$ versus $90 \%$ in the stented versus standard groups, respectively ( $\log \operatorname{rank} P=.1$ ) (Figure $2, A$ ). Cumulative survival in the stented versus standard groups at 1,4 , and 7 years was $86 \%$ versus $81 \%, 78 \%$ versus $78 \%$, and $76 \%$ versus $62 \%(\log$ rank $P=.5)$ (Figure $2, B)$. Therefore, antegrade TEVAR of the DTA during DeBakey type I dissection repair showed a trend toward improved open distal

\begin{tabular}{|l|l|l|l|}
\hline & $\begin{array}{l}\text { Total Distal } \\
\text { Reinterventions } \\
\text { (TEVAR + Open) }\end{array}$ & $\begin{array}{l}\text { Open Distal } \\
\text { Reinterventions }\end{array}$ & $\begin{array}{l}\text { TEVAR Distal } \\
\text { Reinterventions }\end{array}$ \\
\hline $\begin{array}{l}\text { Stented Group } \\
(\mathrm{n}=55) \\
\begin{array}{l}\text { Standard Group } \\
(\mathrm{n}=120)\end{array}\end{array}$ & 11 & 1 & 10 \\
& 16 & 11 & 5 \\
\hline
\end{tabular}

A

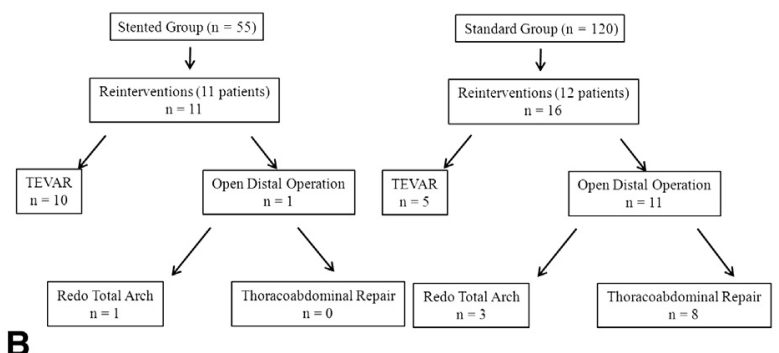

FIGURE 1. Stented versus standard groups: A, Distal aortic reinterventions. B, Distribution of open and endovascular aortic reintervention cases. TEVAR, Thoracic endovascular aneurysm repair.
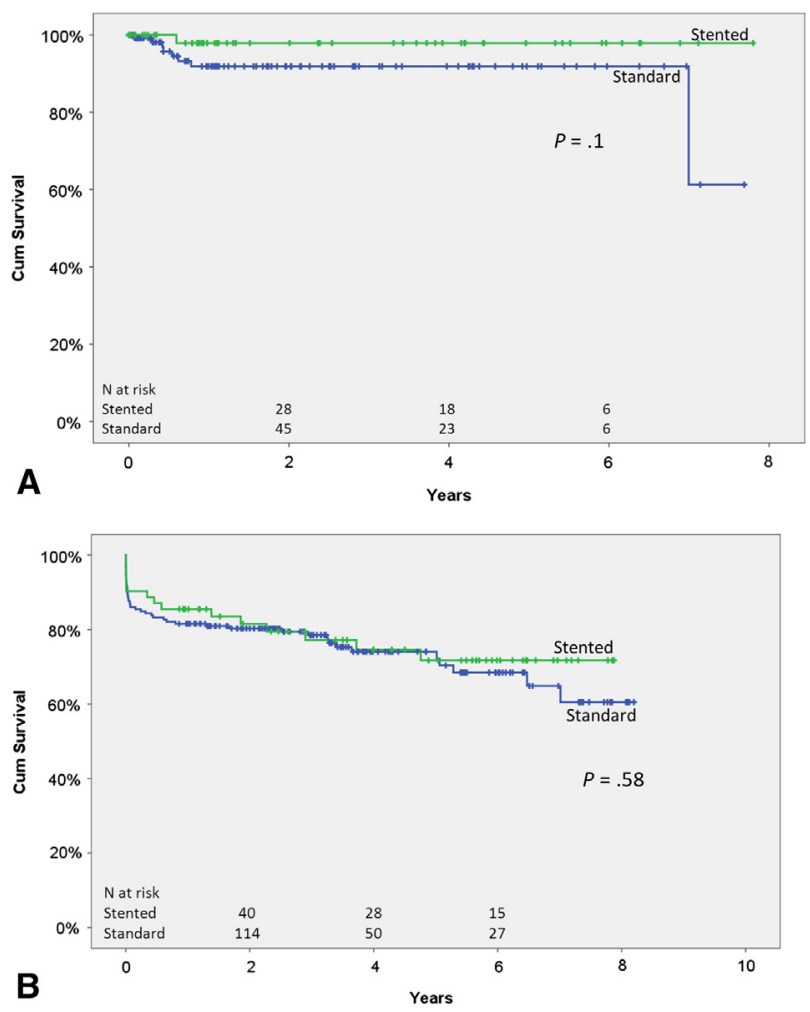

FIGURE 2. Kaplan-Meier survival curves for the stented versus standard groups. A, Freedom from open distal aortic reintervention. B, Cumulative survival.

aortic intervention rate, without increasing early midterm mortality.

\section{DISCUSSION}

The novel concept of concomitant antegrade TEVAR stenting of the proximal DTA during acute DeBakey type I dissection repair at our institution emerged from integration of 2 main factors: patients with type A dissection with severe malperfusion syndrome had higher mortality, partly because the standard repair did not completely address true lumen compression in the DTA, and development of an endovascular platform for treatment of symptomatic type B aortic dissection allowed extension of this technology for treatment of DeBakey type I dissection. Previously, we reported the use of concomitant antegrade TEVAR technique, with equivalent postoperative outcomes, and improved thoracic aortic false lumen obliteration. ${ }^{20}$ Here, we report our midterm outcomes in a concurrent series comparing standard open repair with open repair plus TEVAR. Overall, our findings suggest that concomitant TEVAR during type A dissection repair improves morbidity associated with open distal aortic intervention rate.

Concomitant antegrade TEVAR during DeBakey type I dissection repair can be safely employed, without increasing postoperative morbidity and mortality. ${ }^{21-28}$ 
This study confirms these findings, despite the fact that aortic crossclamp and circulatory arrest times were significantly longer in the stented group. As routine practice at our institution, transverse hemiarch reconstruction under circulatory arrest is performed using RCP under deep hypothermia. ACP via axillary cannulation or direct ostial innominate artery and left carotid artery cannulation is typically used for cases of longer circulatory arrest. Although over the past 3 years use of ACP for standard type A dissection repair is increasingly used at our institution. Therefore, there is discrepancy in the cerebral perfusion strategy in the stented versus standard groups (Table 2). The slightly lower stroke rate seen in the stented group ( $5 \%$ vs $8 \%)$ may be a reflection of the increased use of ACP in the stented group compared with the standard group, although this did not reach statistical significance $(P=.6)$. Also, within the stented group, there were no differences in neurologic outcomes in patients where RCP alone was used compared with ACP alone. Similarly, we did not observe increased permanent paraplegia in the stented group, further attesting to the safety profile of the concomitant antegrade TEVAR technique. Given these findings, our study suggests that manipulation of the aortic arch and DTA during antegrade TEVAR can be safely performed, without increasing postoperative or delayed stroke or paraplegia rates.

Even though antegrade TEVAR was initially used for DTA-related malperfusion, the technique was extended for treatment of aortic arch tears as well and is now more routinely performed based on surgeon preference. Instead of performing a total arch replacement, which can be associated with higher stroke rate and longer circulatory arrest time, coverage of the aortic arch tear can be safely achieved using the antegrade TEVAR technique. With this "modified frozen elephant trunk" approach the proximal end of the stent graft is deployed right at the left subclavian artery take-off along the greater curvature of the aortic arch, and proximally along the lesser curve, the stent graft is integrated into the transverse hemiarch graft suture line. In the Stented group, 19 patients $(31 \%)$ had aortic arch tears that were treated using this modified frozen elephant trunk technique, suggesting that to some extent there was a selection bias in the adoption of this technique for the treatment of DeBakey type I acute aortic dissections with arch tears. There has been 1 patient with an aortic arch complication, where a type IA endoleak occurred secondary to undersizing the stent graft, requiring a delayed open redo total arch operation due to arch dilation. This was the single delayed open distal aortic operation in the stented group. Preoperative CT imaging was not available in that particular case, and stent graft sizing was determined by intraoperative transesophageal dimensions. Since then, we have stopped antegrade TEVAR in cases where preoperative CT imaging is not available, and we perform standard total arch replacement under ACP circulatory arrest. In the standard group, patients undergoing total arch replacement were excluded from this study because these patients constitute a population with even greater morbidity and technical complexity and were deemed not an appropriate control group for comparison. Overall, we believe that this technique of modified frozen elephant trunk can be safely employed for the treatment of DeBakey type I dissection with aortic arch tear instead of a total arch replacement. We have not used this technique in patients with aortopathies such as Marfan syndrome.

False lumen obliteration in the DTA was significantly improved in the Stented group ( $82 \%$ vs $39 \%$ ), even though complete false lumen obliteration was similar in both groups $(27 \%$ vs $23 \%)$. This attests to the fact that even though true lumen in the proximal DTA is stabilized and expanded secondary to antegrade TEVAR, fenestrations in the distal thoracic/abdominal aorta prevent complete false lumen obliteration. Even though false lumen thrombosis is improved with TEVAR, the aortic wall is still pressurized in cases where complete obliteration is not present, and thus it would still be prone to aneurysmal dilation. Therefore, we have maintained close follow-up of the thoracic and abdominal aorta with serial imaging in stented group patients. Future studies looking into the aortic dilation rates in stented versus standard group patients would help ascertain if the improved DTA false lumen thrombosis in the stented group translates into decreased need for frequent CT imaging follow-up.

Overall late distal aortic reintervention rates were higher in the stented group ( $20 \%$ vs $10 \%)$, although majority of the reinterventions were single TEVAR cases. There was 1 open distal aortic reintervention in the stented group, as mentioned above. Of the 10 TEVAR interventions, 8 were performed during the first 2 years of adopting the antegrade TEVAR technique. Since then, over the past 36 stented cases, 2 single TEVAR distal aortic interventions were required. Reasons for this likely include that there is clearly a learning curve associated with adopting this technique. In addition, initially, use of RCP with deep hypothermia during circulatory arrest was used during antegrade TEVAR, which may have affected the nitinol frame expansion under cooler conditions, and thus led to a higher incidence of distal landing zone endoleak. Preferentially, ACP circulatory arrest is used during antegrade TEVAR cases now, which is performed under more moderate hypothermia conditions. This may enable a better seal at the landing zones due to better expansion of the nitinol skeleton of the endograft. Also, at the beginning of our trial 100-mm length stent grafts were used, compared with the $150-\mathrm{mm}$ length stent grafts that we use now. The added coverage in the latter cases may have promoted greater DTA false lumen thrombosis and thus provided better distal seal. Even though TEVAR late distal aortic intervention was significantly higher 
in the stented group, this did not lead to any paraplegia or mortality and no patients required second distal aortic reintervention. Three patients in the standard group required multiple distal aortic reinterventions, with 1 postoperative death.

The most important difference over follow-up between the 2 groups was the open distal aortic operation rates. Of the 16 distal aortic reinterventions in the standard group, 11 were open operations $(7.1 \%$ open distal reoperation rate); compared with 1 out of 11 in the stented group ( $1.7 \%$ open distal reoperation rate). So far, no patients have required extent I, II, or III TAAA repair in the stented group, compared with 7 in the standard group $(P=.1)$. Eight patients $(7 \%)$ in the standard group underwent at least a second circulatory arrest period during their lifetime, compared with $1(1.8 \%)$ in the stented group. The antegrade TEVAR platform at the index operation thus decreased the chance of DeBakey type I dissection patients having to undergo a second episode of circulatory arrest during their lifetime. Therefore, antegrade TEVAR during DeBakey type I dissection repair improved morbidity over midterm follow-up. This finding, in conjunction with the follow-up CT imaging studies, supports the idea that remnant distal aortic dilation occurs more rapidly with standard type A dissection repair than with open repair plus antegrade TEVAR. Most likely this is due to the improved false lumen thrombosis achieved in the stented group. One would expect higher pressurization of the aortic wall with a patent false lumen compared with a thrombosed false lumen. Larger sample size and longer follow-up will be required before we can further validate this idea clinically. Interestingly, reducing open distal aortic interventions did not improve survival over midterm follow-up in the stented group. Longer follow-up with a larger sample size is required to see if the potential benefit of improved thoracic false lumen obliteration achieved with antegrade TEVAR will translate into a survival benefit.

Further, when we compared the mean hospital length of stay in patients undergoing distal aortic reintervention (ie, TEVAR and open cases), the standard group patients had significantly longer length of stay due to the higher open distal aortic operation rate $(P=.002)$. In the stented group, median hospital stay was 5 days, with mean of $11 \pm 14$ days. In the standard group, median stay was 18 days, with mean of $19 \pm 8$ days. Therefore, from a cost analysis standpoint, the cost of TEVAR stent graft at the index operation in the stented group is most likely offset by decreasing the cost associated with open distal aortic reoperation, which is associated with longer operative times and increased hospital length of stay.

One of the weaknesses of this study is the incomplete follow-up in the standard group (77\%) compared with the stented group $(98 \%)$. Although we are unaware of any other reports concurrently comparing midterm outcomes in
DeBakey type I dissection repair techniques of stenting versus nonstenting. Although this is a single institution experience, individual surgeon preference played an important role in determining which patient received antegrade TEVAR versus not during DeBakey type I dissection repair, and the circulatory arrest management strategy also varied by surgeon preference. Therefore, this point has to be taken into consideration. With further follow-up, if there is consistent improvement in morbidity associated with open repair + antegrade TEVAR, and this translates to improved mortality, then likely a randomized trial comparing the 2 DeBakey type I dissection repair platforms is warranted.

The authors thank Patrick Moeller and Rohan Menon for providing database management.

\section{References}

1. Elefteriades JA. Natural history of thoracic aortic aneurysms: indications for surgery, and surgical versus nonsurgical risks. Ann Thorac Surg. 2002;74:S1877-80 discussion S1892-8.

2. Kouchoukos NT, Masetti P, Rokkas CK, Murphy SF, Blackstone EH. Safety and efficacy of hypothermic cardiopulmonary bypass and circulatory arrest for operations on the descending thoracic and thoracoabdominal aorta. Ann Thorac Surg. 2001;72:699-708

3. Safi HJ, Harlin SA, Miller CC, Iliopoulos DC, Joshi A, Mohasci TG, et al. Predictive factors for acute renal failure in thoracic and thoracoabdominal aortic aneurysm surgery. J Vasc Surg. 1996;24:338-45.

4. Geirsson A, Bavaria JE, Swarr D, Keane MG, Woo YJ, Szeto WY, et al. Fate of the residual distal and proximal aorta after acute type a dissection repair using a contemporary surgical reconstruction algorithm. Ann Thorac Surg. 2007;84 1955-64.

5. Bavaria JE, Pochettino A, Brinster DR, Gorman RC, McGarvey ML, Gorman JH, et al. New paradigms and improved results for the surgical treatment of acute type A dissection. Ann Surg. 2001;234:336-43.

6. Kirsch M, Soustelle C, Houël R, Hillion ML, Loisance D. Risk factor analysis for proximal and distal reoperations after surgery for acute type A aortic dissection. $J$ Thorac Cardiovasc Surg. 2002;123:318-25.

7. Bowen F, Szeto W, Pochettino A, Bavaria JE. Application of the open arch antegrade "stented elephant trunk" approach for hybrid repair of the aortic arch using the Gore TAG stent graft in Type A dissections. In: Proceedings from the 86th Annual Meeting of The American Association for Thoracic Surgery. Beverly, MA: American Association for Thoracic Surgery; 2006:224.

8. Stecker MM, Cheung AT, Pochettino A, Kent GP, Patterson T, Weiss SJ, et al. Deep hypothermic circulatory arrest: I. Effects of cooling on EEG and evoked potentials. Ann Thorac Surg. 2001;71:14-21.

9. Stecker MM, Cheung AT, Pochettino A, Kent GP, Patterson T, Weiss SJ, et al. Deep hypothermic circulatory arrest: II. Changes in EEG and evoked potentials during rewarming. Ann Thorac Surg. 2001;71:22-8.

10. Kazui T, Washiyama N, Muhammad B, Terada H, Yamashita K, Takinami M, et al. Total arch replacement using aortic arch branched grafts with the aid of antegrade selective perfusion. Ann Thorac Surg. 2000;70:3-9.

11. Tsai TT, Evangelista A, Nienaber CA, Trimarchi S, Sechtem U, Fattori R, et al. Long-term survival in patients presenting with type A acute aortic dissection: insights from the International Registry of Acute Aortic Dissection (IRAD). Circulation. 2006;114(1 Suppl):I350-6

12. Knipp B, Deeb M, Prager R, Williams C, Upchurch G, Patel H. A contemporary analysis of outcomes for operative repair of type A aortic dissection in the United States. Surgery. 2007;124:524-8.

13. Watanuki H, Ogino H, Minatoya K, Matsuda H, Sasaki H, Ando M, et al. Is emergency total arch replacement with a modified elephant trunk technique justified for acute type A aortic dissection? Ann Thorac Surg. 2007;84:1585-91.

14. Sueyoshi E, Sakamoto I, Hayashi K, Yamaguchi T, Imada T. Growth rate of aortic diameter in patients with type B aortic dissection during the chronic phase Circulation. 2004;110(11 Suppl 1):II256-61

15. Nienaber CA, Zannetti S, Barbieri B, Kische S, Schareck W, Rehders TC INSTEAD study collaborators. INvestigation of STEnt grafts in patients with 
type B Aortic Dissection: design of the INSTEAD trial-a prospective, multicenter, European randomized trial. Am Heart J. 2005;149:592-9.

16. Czermak BV, Mallouhi A, Perkmann R. Serial CT volume and thrombus length measurements after endovascular repair of Stanford type B aortic dissection. J Endovasc Ther. 2004;11:1-12.

17. Szeto WY, McGarvey M, Pochettino A, Moser GW, Hoboken A, Cornelius K, et al. Results of a new surgical paradigm: endovascular repair for acute complicated type B aortic dissection. Ann Thorac Surg. 2008;86:87-94.

18. Kusagawa H, Shimono T, Ishida M, Suzuki T, Yasuda F, Yuasa U, et al. Changes in false lumen after transluminal stent-graft placement in aortic dissections: six years' experience. Circulation. 2005;111:2951-7.

19. Eggebrecht H, Nienaber CA, Neuhäuser $M$, Baumgart D, Kische S, Schmermund A, et al. Endovascular stent-graft placement in aortic dissection: a meta-analysis. Eur Heart J. 2006;27:489-98.

20. Pochettino A, Brinkman WT, Moeller P, Szeto WY, Cornelius K, Bowen FW, et al. Antegrade thoracic stent grafting during repair of acute DeBakey I dissection prevents development of thoracoabdominal aortic aneurysms. Ann Thorac Surg. 2009;88:482-90.

21. Lin PH, Dardik A, Coselli JS. A simple technique to facilitate antegrade thoracic endograft deployment using a hybrid elephant trunk procedure under hypothermic circulatory arrest. J Endovasc Ther. 2007;14:669-71.

22. Jakob H, Tsagakis K, Tossios P, Massoudy P, Thielmann M, Buck T, et al. Combining classic surgery with descending stent grafting for acute DeBakey type I dissection. Ann Thorac Surg. 2008;86:95-101.

23. Gorlitzer M, Weiss G, Thalmann M, Meertikian G, Wislocki W, Meinhart J, et al. Combined surgical and endovascular repair of complex aortic pathologies with a new hybrid prosthesis. Ann Thorac Surg. 2007;84:1971-6.

24. Jakob H, Tsagakis K. DeBakey type I dissection: when hybrid stent-grafting is indicated? J Cardiovasc Surg (Torino). 2010;51:633-40.

25. Roselli EE, Soltesz EG, Mastracci T, Svensson LG, Lytle BW. Antegrade delivery of stent grafts to treat complex thoracic aortic disease. Ann Thorac Surg. 2010;90:539-46.

26. Shi E, Gu T, Yu L, Xiu Z, Zhang Z, Wang C, et al. Repair of Stanford type A aortic dissection with ascending aorta and hemiarch replacement combined with stentgraft elephant trunk technique by using innominate cannulation. J Thorac Cardiovasc Surg. 2011;142:1458-63.

27. Czerny M, Stöhr S, Aymard T, Sodeck GH, Ehrlich M, Dziodzio T, et al. Effect on false-lumen status of a combined vascular and endovascular approach for the treatment of acute type A aortic dissection. Eur J Cardiothorac Surg. 2012;41: 409-13.

28. Masseli F, Wilhelm K, Probst C, Schiller W. Open antegrade aortic stent implantation after surgical treatment in type A aortic dissection. J Thorac Cardiovasc Surg. 2012;144:1527-30.

\section{Discussion}

Dr G. Chad Hughes (Durham, $N C$ ). I would like to thank the Association for the opportunity to discuss this work and congratulate Joe on a great presentation. Joe and Alberto, great work. I just have a few questions.

Although the authors state their initial experience has led them to use this technique more widely, it was used in only $26 \%$ of the 242 patients undergoing Debakey type I dissection repair during this time interval. This indicates the presence of bias with regard to patient selection, surgeon preference, or both. Please describe in more detail how patients are selected to undergo this procedure because it would appear that the vast majority still do not receive this adjunctive antegrade stent graft repair.

Dr Bavaria. That is a very fair question. That gets into the methods of selection a little bit, and there was a little bit of an evolution-especially in the really early phases.

The first 6 we did were actually done for significant malperfusion problems, and when we looked at them-this was presented at the Annual Meeting of The American Association for Thoracic Surgery in 2006-we saw that we had very good remodeling. This was the impetus for the entire effort. The fact of the matter is, in our institution there are 5 aortic surgeons who take dissection call; 2 of them do the procedure and 3 of them do not. So that's the natural selection bias right there; the patients come in randomly.

The other selection bias is that we do not do Marfan patients, so the entire Marfan subgroup was excluded, and that's about $15 \%$ of cases. We do not perform the procedure in patients we believe will have $<10$-year life expectancy from their age.

An analysis probably should be done to take out that side. But that is the actual selection algorithm right there.

Dr Hughes. Yes. I would say if there is institutional buy-in, I would question why 3 of the surgeons don't do it.

Dr Bavaria. That's a good question. I can't answer that.

Dr Hughes. Okay. We'll move on.

Dr Bavaria. I think they're a little younger and may not be as self-secure.

Dr Hughes. Yeah, got it.

Although the postoperative outcomes as presented suggest no adverse effects of the addition of antegrade stent graft deployment to standard dissection repair, the results are unadjusted and do not take into account potential differences in the risk profiles of the groups.

For example, the incidence of preoperative renal failure was nearly double in the standard versus stented group, and the incidence of preoperative shock or performance of concomitant coronary artery bypass grafting was not reported, all of which are predictors of composite mortality or major morbidity following proximal aortic replacement based on data from more than 45,000 patients in the Society of Thoracic Surgeons database, which we recently published in Journal of The American College of Cardiology.

Further, the International Registry of Acute Aortic Dissection has previously published a risk model for type A dissection repair that could be used to risk adjust the patient cohorts, or ideally, the analysis could be repeated with a propensity-matched design that would better account for any potential differences between the groups. Please comment on that.

Dr Bavaria. We went through the univariate analysis of the preoperative risk factors, and there wasn't anything that was below 0.05 .

But I totally agree with you. The next iteration should be a propensity-matched analysis, and I totally agree that we should do a little bit more robust analysis of preoperative factors to make sure that we are comparing apples to apples here, and I think a propensity analysis is perfect.

At some point we are probably going to have to do a prospective randomized study on this. I think the equipoise is satisfactory enough to do that. That probably will require a multicenter trial.

Dr Hughes. That gets to my last question: Although the decreased need for open reintervention is interesting, it seemed somewhat less compelling in the absence of the survival benefit. Do you have any thoughts on why you're not seeing a survival benefit at this point?

Dr Bavaria. That is a very good question. I do not know why there is not a survival benefit. You might think there should be. Some of this may be because there was a significant learning curve with the original 10 or 15 cases. We had to do some interventions because we were placing the stents too distally, and as Eric Roselli 
has taught us, it may be better to bring these stents a lot more proximal-we figured that out.

We basically cover the subclavian artery. We bring it as far proximal as possible. We don't cut out the graft like Eric does, but we do bring them as far proximal as possible.

That was probably something that affected the mortality rate on the stented side at the beginning of the series. I do not really know the answer. We'll see.

Dr Hughes. Well, again, congratulations, and I echo your sentiment. I think this would be well suited to a multicenter randomized trial.

Dr Bavaria. Thank you very much, Chad.

Dr Marc R. Moon (St Louis, Mo). Joe, does this have to be a covered stent graft? Couldn't you just put in a stent? Wouldn't it effectively do the same thing?

Dr Bavaria. One of the reasons why it works in these selected patients is because many times there is a large fenestration in the proximal descending aorta that we cannot get to.

So if you have a large fenestration in the proximal descending aorta, then a pure stent would maybe not work as well. It would theoretically work as well if there were not a large communication in the proximal descending aorta. But if you have a large communication in the proximal descending aorta, then you need a fully covered stent.

Dr Alberto Pochettino (Rochester, Minn). I just want to make a couple of comments, because I was involved in this study.

The first issue raised regarding patient selection is a good one, and I want to emphasize that this was a work in progress. The first 8 to 10 patients were indeed what I would call a pilot project; most were patients who definitely had malperfusion and needed something more than a standard operation. We were impressed with how good the results were in those initial, intrinsically high-risk patients.

What came down within the University of Pennsylvania was that 1 of the surgeons-myself-went on to generalize the use of this technique to all Debakey type I dissections, with the only exclusion being collagen vascular disease. The remaining surgeons were not compelled to embark on a modification that makes an operation that is intrinsically difficult even more difficult and increases the circulatory arrest time by about 20 minutes, without clear-cut, up-front evidence that it would be of benefit.

Ultimately, as the results improved, some of the other surgeons, Bavaria being one of them, started using the antegrade stent technique.

As we think back, the issue remains as to whether or not this technique is worthwhile. I don't as yet know the answer. I've been impressed that the technique is safe and reproducible, with equivalent results to the standard type A repair.

As we analyze the long-term outcomes most of the patients in the 2 groups, aside from the early pilot project, are indeed similar in presentation and early outcomes. I don't remember seeing a particular bias regarding the stented group being sicker or not as sick compared with the other groups. Again, the early pilot project was a little bit different.

Dr Anthony Estrera (Houston, Tex). Joe, nice job. The concept is good. I do like the concept, and if the data of the Investigation of Stent Grafts in Patients With Type B Aortic Dissection trial bears out as Nienaber has presented most recently at 5 years is anything to go by, you should see a difference as your data matures.

My question is related to spinal cord ischemia and paraplegia. Although it wasn't significant, the $P$ value was .07 . Because the stent-graft is thrombosing-remodeling-all those relevant intercostals - what are your thoughts about paraplegia and was your study powered enough to show a difference?

Dr Bavaria. We probably do not have enough data right now. I have a slide I didn't show that is not just the survival differences between the 2 groups as far as the learning curve is concerned, but also the entire morbidity and mortality profile in the learning curve.

We had 5 spinal cord ischemic events, and all 4 of those were in the first part of the series. And that's why at the beginning we didn't know how long the stents should be, and now we've kind of standardized that. But you're right, it is an issue.

Dr Eric E. Roselli (Celevand, Ohio). Joe, great presentation. Just 2 really quick questions.

Despite the fact that you show there was more malperfusion and longer circulatory arrest times in your stented patients, there was really no difference in mortality. Did you do any additional adjunctive procedures like stenting any static occlusions of organs downstream at the same time in any of your patients?

Dr Bavaria. No, we did not. The only adjunct is that we are doing more and more of these operations in the endo suite now, so when we put a stent in, we'll shoot a completion angiogram.

Dr Roselli. Great. I think that's an important part of the procedure. A serendipitous finding in my series was that I think we can treat these patients with malperfusion better using the hybrid suite.

My second question concern folks who had persistent false lumen perfusion in the stented area on follow-up. Have you done an imaging analysis to see if they had persistent dissection in the branch vessels of their arches? I suspect that may be a common area where a persistent entry tear was filling the false lumen of the aorta.

Dr Bavaria. I agree with that concept. I think the differential between my technique-or our technique-and maybe even your technique and Di Bartolomeo's technique right behind you, is that they're doing a total arch, and they have a sewn-in graft where there is no communication. In other words, there is no landing zone in this dissected aorta.

We're getting into the mid-70s pretty consistently; between $70 \%$ and $80 \%$ success. But we have $20 \%$ to $25 \%$ nonsuccess compared with what Roberto is going to tell us, probably $10 \%$ with a full elephant trunk graft that is made for this.

So I think you're right. There are either left subclavian or type $1 \mathrm{~A}$ endoleak situations that you can think about. We had more of these in the early phase because we learned a lot and put them up more proximally now.

Dr Moon. Hopefully you've decreased the pressure so much in that false lumen that it's not going to be a problem and dilate over time like it would be if you didn't have the stent in there.

Dr Bavaria. I agree. I think that differential between putting a stent in antegrade under a hemiarch condition compared with a total arch with a designed E-Vita type of graft (JOTEC, Hechingen, Germany), that does explain the differential, which is about $15 \%$. 
Dr Moon. How much contrast do you do on your completion angiogram? What can you do?

Dr Bavaria. As little as possible.

Dr Moon. Fifteen for 30?

Dr Bavaria. Yes.

Dr Roselli. Mine is $12.5 \mathrm{cc}, 15$ for 25 with half-strength contrast.

Dr Bavaria. Ten for 30 or something like that. Right at the end of the stent so it doesn't get hung up.

Dr Roberto Di Bartolomeo (Bologna, Italy). Joe, my compliments on your presentation and your technique. What do you think about our initial experience in type B acute aortic dissection with impending rupture and/or visceral malperfusion to use the frozen elephant trunk technique?

Dr Bavaria. For type B?
Dr Di Bartolomeo. Yes, for type B acute dissection when there is impending rupture or/and distal malperfusion.

Dr Bavaria. With the E-Vita?

Dr Di Bartolomeo. Yes.

Dr Bavaria. Yes, it makes sense.

Dr Di Bartolomeo. Seventy percent of patients have the acute aortic dissection in the ascending aorta, and $22 \%$ start in the descending aorta. With our operation, the frozen elephant trunk, using the E-Vita-or now the Thoraflex, the new device from Vascutek (Renfrewshire, Scotland)_it's possible to remove the ascending aorta and aortic tissue in the same operation, also reducing the risk of the type $\mathrm{A}$ aortic dissection. Is it a good idea?

Dr Bavaria. I think that is going to be the topic of our next research project. That's a nice segue. 